\title{
Novel Design of Non-Enzymatic Sensor for Rapid Monitoring of Hydrogen Peroxide in Water Matrix
}

\author{
A.B.M. Zakaria ${ }^{1}$, Danuta Leszczynska ${ }^{2^{*}}$ \\ ${ }^{1}$ Department of Chemistry and Biochemistry, Jackson State University, Jackson, MS 39217,USA, \\ email:abmzakaria@icnanotox.org \\ ${ }^{2}$ Department of Civil and Environmental Engineering, Jackson State University, Jackson, MS \\ 39217,USA, email:danuta.leszczynska@jsums.edu \\ *Corresponding author. Tel:+1-601-979-1091; E-mail: danuta.leszczynska@jsums.edu
}

\begin{abstract}
A simple and reliable design of the non-enzymatic sensor capable of instant detection of broad range of hydrogen peroxide $\left(\mathrm{H}_{2} \mathrm{O}_{2}\right)$ concentrations in various water-based matrixes has been presented. Manufacturing of the sensor was based on the manganese dioxide $\left(\mathrm{MnO}_{2}\right)$-nonfunctionalized single walled carbon nanotubes (SWCNTs) - Nafion nanocomposite modified glassy carbon electrode $\left(\mathrm{MnO}_{2} / \mathrm{SWCNTs}-\mathrm{Nf} / \mathrm{GCE}\right)$. The electrochemical behavior of hydrogen peroxide at this sensitive platform was verified by the cyclic voltammetry and amperometry. The obtained results have demonstrated that the modified GCE exhibited an excellent electrocatalytic activity toward hydrogen peroxide. The parameters related to this sensor, such as amount of $\mathrm{MnO}_{2}$, applied potential and $\mathrm{pH}$ value were optimized to attain a broad working linear range $5.0 \times 10^{-6}$ to $3.0 \times 10^{-3} \mathrm{M}$, with detection limit of $0.52 \times 10^{-6} \mathrm{M}(17.7 \mathrm{ppb})$ of detection $\mathrm{H}_{2} \mathrm{O}_{2}$. Developed electrode was tested for stability and accuracy measurements in environmental/biological conditions, such as $\mathrm{pH}$ and interference of common ions, namely calcium, magnesium, nickel, copper, bicarbonate and citrate, showing an excellent stability and repeatability in tested ranges.
\end{abstract}

Keywords: Non-enzymatic Sensor, Amperometry, $\mathrm{H}_{2} \mathrm{O}_{2}$, SWCNT, $\mathrm{MnO}_{2}$, Nafion 


\section{Graphical Abstract}

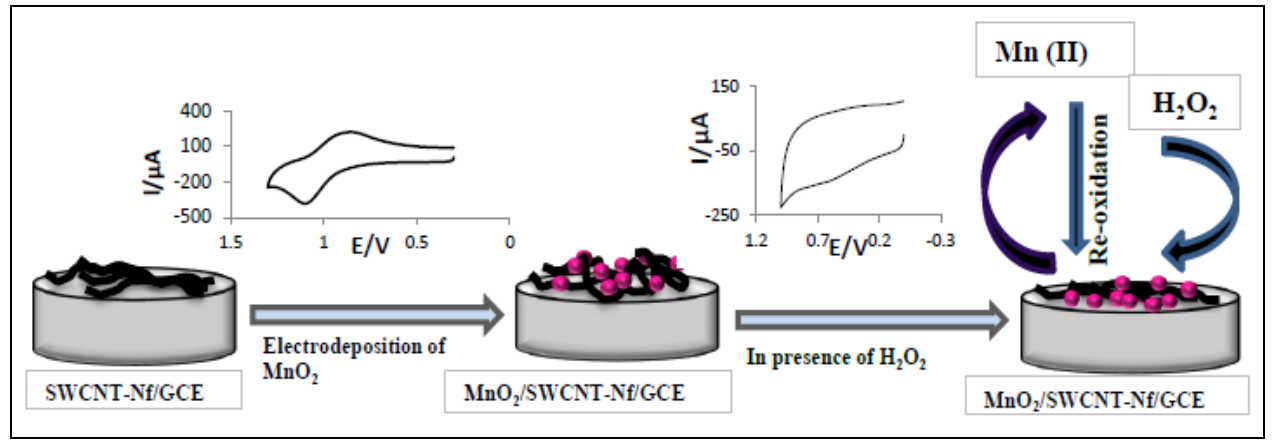

\section{Introduction}

Hydrogen peroxide $\left(\mathrm{H}_{2} \mathrm{O}_{2}\right)$ is commonly known as universal oxidant widely applied in many industrial and environmentally oriented processes. It is also recognized as an essential intermediate in the various environmental and biological reactions [1]. Examples of general environmental applications could include an injection of $\mathrm{H}_{2} \mathrm{O}_{2}$ into the subsurface to supply oxygen for aerobic bioremediation, or use as disinfectant in water and wastewater treatment [2]. Moreover, hydrogen peroxide is found in several household products, such as general-purpose disinfectants, chlorine-free bleaches, fabric stain removers, or hair dyes. Consequently, the dynamic monitoring of changing concentrations of $\mathrm{H}_{2} \mathrm{O}_{2}$ with a sensitive, selective, rapid, and economic method is of great importance to study the reaction's progresses in different conditions [3-9].

There are number of analytical methods available for determination of hydrogen peroxide, such as titrimetry[10], fluorescence [11-14], spectrophotometry[15-18], chemiluminescence [19-21], and electrochemical methods [22-24]. Among them, electrochemical method based on various sensing materials is an attractive option due to its high sensitivity and selectivity, low cost, operational simplicity and real-time monitoring. However, common sensors based on enzymes or proteins have substantial drawbacks, such as complex fabrication procedures, limited lifetime, and poor stability. Currently, the enzyme-free electrodes are being developed with the aim to 
produce non-enzymatic hydrogen peroxide sensor with low detection limit and wide linearity range.

Carbon nanotubes (CNTs) are considered as a promising candidates for the next generation of electrochemical sensors due to their unique properties including large current density, low capacitance and wide potential window [25]. The electronic properties of CNTs are strongly affected by their surface structure, namely, the number of defective sites and functional groups on the side walls and the ends of CNTs. The functional groups (carboxyl, epoxide and hydroxyl) on carbon nanotubes surfaces have major contributions in nanocomposite formation [26, 27]. A series of functionalized CNT-based modified electrode have been reported including CNTepoxy composite electrode [28], $\mathrm{CNT}-\mathrm{Fe}_{3} \mathrm{O}_{4}$ hybrid electrode [29], CNT-cellulose composite electrode [30], CNT-copper hybrid electrode [31], CNT-Prussian blue paste electrodes [32], CNT-graphene-Pt NPs hybrid paper electrode [33] etc. The modified CNT-based electrodes, namely nanocomposites with metal oxides, have been well-accepted as sensing materials due to their long-term stability, and high electron transfer of sensing interface [34]. Various metal oxides, such as copper oxide [35], zirconium oxide [36], ruthenium oxide [37], cobalt oxide [38], cadmium oxide [39], or iron oxide [40], have been introduced by the cyclic oxidation-reduction on nanotubes arrays, which created novel properties for nanotubes arrays, and promised a wide range of technical applications.

Among of available metal oxides, the increasing research efforts have been focused on $\mathrm{MnO}_{2}$ as an alternative low-cost transition-metal oxide, because of its high energy density, environmental compatibility and natural abundance [41]. $\mathrm{MnO}_{2}$ is also an attractive inorganic material that shows the electrocatalytic ability towards $\mathrm{H}_{2} \mathrm{O}_{2}$ [42]. Consequently, the $\mathrm{MnO}_{2}$-SWCNTs modified electrode would be a good choice in developing $\mathrm{H}_{2} \mathrm{O}_{2}$ sensor. To date, number of reports has already been published. For examples, Mahmoudian et al.[43] investigated the $\mathrm{MnO}_{2}$-NTs/RGO nanocomposite as the electrode material prepared by hydrothermal process in acidic $\mathrm{KMnO}_{4}$ solution; Liqiang et al. [44] fabricated the glassy carbon electrode with $\mathrm{MnO}_{2^{-}}$ ordered mesoporous carbon, Liu et al.[45] used Mn-NTA nanowires synthesized by hydrothermal route, Zhang et al.[46] demonstrated Ag-HNTs- $\mathrm{MnO}_{2}$ composite-based modified electrode, and $\mathrm{Xu}$ et al.[47] reported $\mathrm{MnO}_{2}$-modified vertically aligned multi-walled carbon 
nanotubes to evaluate electrocatalytic activity towards $\mathrm{H}_{2} \mathrm{O}_{2}$. However, all these methods require exhaustive synthesis' protocols with series of chemical treatments to achieve the final supporting electrode's substrate. In comparison, the method employed in manufacturing of our sensor, namely, electrodeposition of metal oxide on conductive surface (e.g. CNT), is simple, costeffective, and more suitable in controlling thickness and orientation in terms of size and shape of nanoparticles on supporting electrode.

In this work, we report a simple, but reliable manufacturing of a non-enzymatic hydrogen peroxide sensor, which could be employed for the real-time electrochemical detection of

hydrogen peroxide in complex matrixes, such as environmental or biological samples. Our sensor has been fabricated by the electrodepositing of $\mathrm{MnO}_{2}$ nanoparticles on SWCNT-Nafion nanocomposite coated on Glassy Carbon Electrode. During second part of this study, we have extensively characterized properties, conditions, detection limits and stability of fabricated sensor.

\section{Materials and methods}

\subsection{Reagents}

Single-walled carbon nanotubes (non-functionalized, purity $>90 \mathrm{wt} \%$, outer diameter 1-2 nm, length 5-30 $\mu \mathrm{m}$ ) were purchased from Cheap Tubes Inc. Vermont, USA. Nafion (perfluorinated ion-exchange resin) was obtained from Aldrich as $5 \mathrm{wt} \%$ solution in a mixture of lower aliphatic alcohols and water. Other reagents, such as $\mathrm{H}_{2} \mathrm{O}_{2}(30 \%), \mathrm{MnSO}_{4}, \mathrm{Na}_{2} \mathrm{SO}_{4}, \mathrm{KCl}, \mathrm{Na}_{2} \mathrm{HPO}_{4} .7 \mathrm{H} 2 \mathrm{O}$ and $\mathrm{KH}_{2} \mathrm{PO}_{4}$ were purchased from Sigma-Aldrich (USA). Stock standard solutions of $\mathrm{Na}_{2} \mathrm{HPO}_{4} .7 \mathrm{H}_{2} \mathrm{O}$ and $\mathrm{KH}_{2} \mathrm{PO}_{4}$ were prepared to make phosphate buffer solutions (PBS) of desired $\mathrm{pH}$, and were used as supporting electrolyte. All chemicals were analytical grade, and deionized water was used for preparing all stock solutions throughout the experiments.

\subsection{Apparatus}

Amperometric and cyclic voltammograms were carried out with $\mathrm{CH}$ Instruments $(\mathrm{CHI} 440, \mathrm{CH}$ Instruments, Austin, TX) using a conventional three-electrode system. Modified glassy carbon electrode (GCE), Ag/AgCl/saturated $\mathrm{KCl}$ (Model CH111, CH Instruments, Austin, TX), and a platinum wire were used as working, reference and counter electrodes, respectively. High purity argon was used to deoxygenate all experimental solutions for $20 \mathrm{~min}$, and maintaining argon 
atmosphere during measurements. The morphology and microstructure of the as-prepared $\mathrm{MnO}_{2}$ was characterized by X-ray diffraction (Rigaku Ultima III X-ray Diffraction System, 2.2kW Long-Fine Focus X-ray Tube, Graphite Monochromator and Scintillation Detector) and scanning electron microscopy (ZEISS Supra 40VP SEM).

\subsection{Preparation of $\mathrm{MnO}_{2} / \mathrm{SWCNT}-\mathrm{Nf} / \mathrm{GCE}$}

One milligram of SWCNT (non-functionalized) was dispersed in $1 \mathrm{ml}$ of Nafion under $20 \mathrm{~min}$ constant ultrasonic agitations to prepare $1 \mathrm{mg} / \mathrm{ml}$ black homogeneous suspension. The glassy carbon electrode was carefully polished with $0.05 \mu \mathrm{m}$ alumina powder, and then rinsed successively with ethanol and deionized water. After that, a $3 \mu \mathrm{L}$ of the black suspension was dropped on to the surface of cleaned GC electrode and dried under a yellow lamp with $50^{\circ} \mathrm{C}$ to obtain the SWCNT-Nf/GCE. Then $\mathrm{MnO}_{2}$ was electrodeposited on the surface of SWCNTNf/GCE by repetitive scanning cycles by applying potential window of 0.3 to $1.3 \mathrm{~V}$ in a solution of $0.1 \mathrm{M} \mathrm{Na}_{2} \mathrm{SO}_{4}$ and $5 \mathrm{mM} \mathrm{MnSO}$. Several electrodes were prepared according this procedure. Fig. 1 is presenting schematics of process and steps of preparation of modified Glassy Carbon Electrode (GCE).

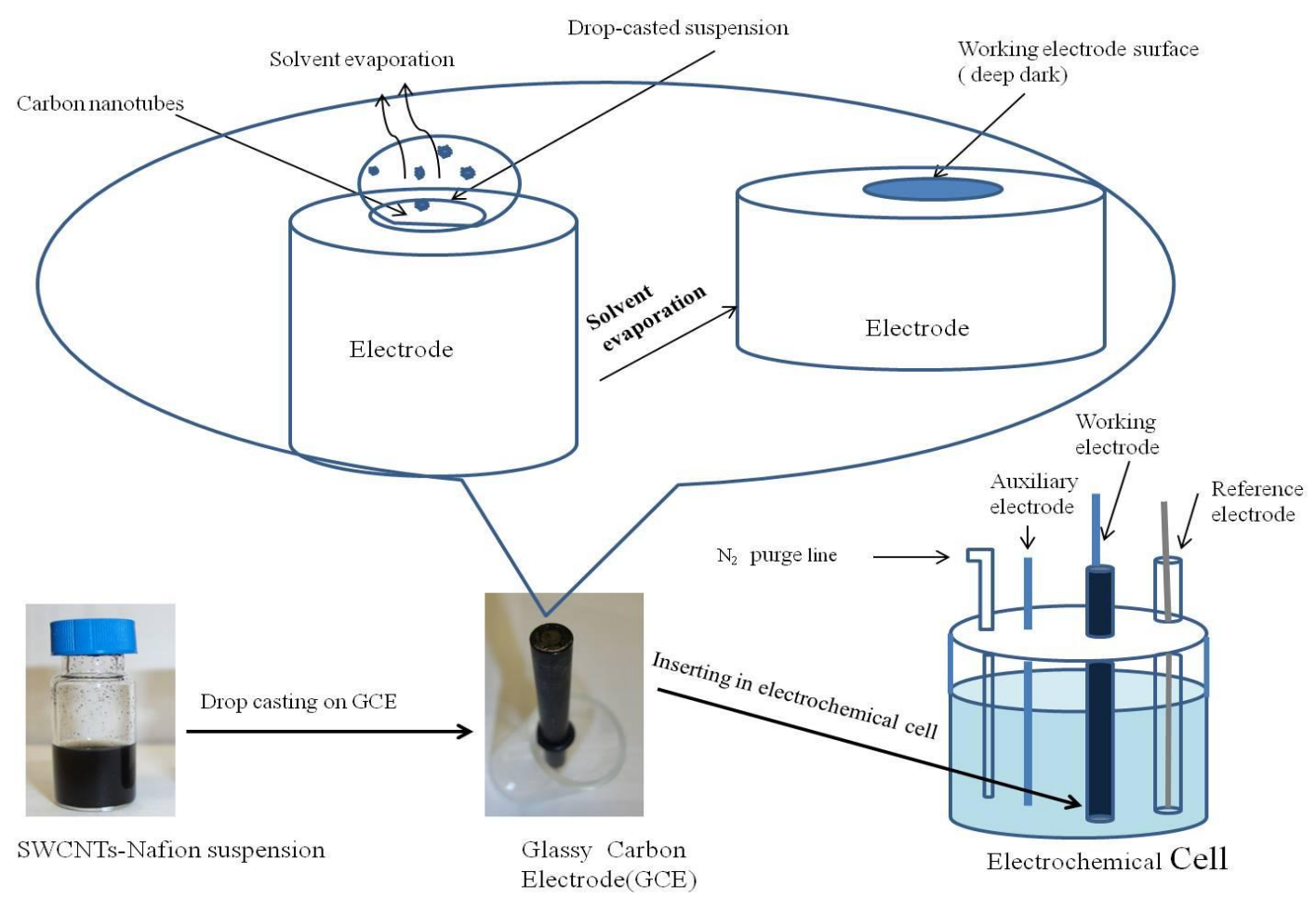

Fig.1. Schematic representation of preparation modified Glassy Carbon Electrode (GCE). 


\section{Results and discussion}

\subsection{Evaluation of the sensor}

\subsubsection{Formation and characterization of $\mathrm{MnO}_{2}$ nanostructured film}

Fig. 2 (A) shows the cyclic voltammograms (CVs) obtained in $0.1 \mathrm{M} \mathrm{Na} \mathrm{SO}_{4}$ on bare GCE (a) and SWCNT-Nf/GCE (b) without containing $5.0 \mathrm{mM} \mathrm{MnSO}_{4}$ in the potential window of 0.3 to $1.3 \mathrm{~V}$ vs. $\mathrm{Ag} / \mathrm{AgCl}$ at scan rate $100 \mathrm{mV} \mathrm{s}^{-1}$. No redox peak was observed on both voltammograms except the capacitive behavior of SWCNT-Nf/GCE due to the presence of SWCNT on electrode surface. Moreover, in presence of $5.0 \mathrm{mM} \mathrm{MnSO}_{4}$ at SWCNT-Nf/GCE, a broad anodic and cathodic peak were observed at around $+1.08 \mathrm{~V}$ and $+0.8 \mathrm{~V}$ respectively.
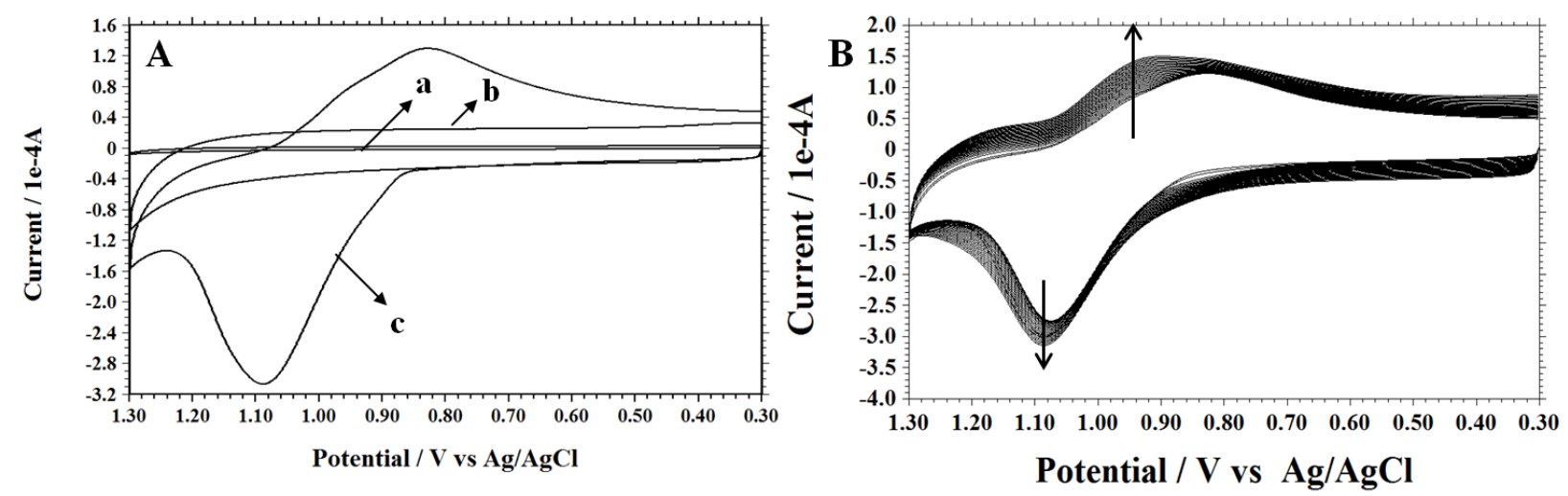

Fig. 2. (A) Cyclic voltammograms (CVs) obtained in $0.1 \mathrm{M} \mathrm{Na} 2 \mathrm{SO}_{4}$ solution at (a) bare GCE, (b) SWCNT-Nf/GCE in absence and (c) SWCNT-Nf/GCE in presence of $5.0 \mathrm{mM} \mathrm{MnSO}_{4}$ at scan rate of $100 \mathrm{mV} \mathrm{s}^{-1}$; (B) repetitive scanning cycles for electrodeposition of $\mathrm{MnO}_{2}$ on SWCNTNf/GCE.

The anodic peak indicates the oxidation of $\mathrm{Mn}(\mathrm{II})$ to $\mathrm{Mn}(\mathrm{III})$, and on the reverse scan the cathodic peak was due to the reduction of $\mathrm{Mn}(\mathrm{III})$ to $\mathrm{Mn}(\mathrm{II})$. The current ratio of oxidation and reduction $\left(I_{p a} / I_{p c}\right)$ was about 1.90 , and the peak-to-peak separation value $\left(\mathrm{E}_{\mathrm{pa}}-\mathrm{E}_{\mathrm{pc}}\right)$ was approximately $260 \mathrm{mV}$, indicating that the redox of $\mathrm{Mn}(\mathrm{II}) / \mathrm{Mn}(\mathrm{III})$ is a quasi-reversible reaction. With further cycling, as shown in Fig.1(B), a disproportionate reaction of $\mathrm{Mn}$ (III) with water could yield $\mathrm{Mn}$ (II) and $\mathrm{MnO}_{2}$, and the resultant $\mathrm{MnO}_{2}$ was precipitated on GC electrode surface. The reaction is provided by Eq.(1):

$2 \mathrm{Mn}(\mathrm{III})+2 \mathrm{H}_{2} \mathrm{O} \rightarrow \mathrm{Mn}(\mathrm{II})+\mathrm{MnO}_{2}+4 \mathrm{H}^{+}$

The intensity of oxidation and reduction increased along with continuation of cycles, and it shifted due to altering electrode's surface with deposition $\mathrm{MnO}_{2}$. All this observations are 
consistent with previous reports.[48, 49] To confirm the surface's modification with $\mathrm{MnO}_{2}$ on SWCNT-Nf/GCE, we carried out scanning electron microscope (ZEISS Supra 40 VP SEM) with an accelerating voltage of $5.00 \mathrm{KeV}$. As shown in Fig. 3, bright rice-like $\mathrm{MnO}_{2}$ with an average size of $\sim 3.0 \mu \mathrm{m}$ were firmly electrodeposited on the surface of SWCNT modified GC electrode after 30 cycles of cyclic voltammetry. Moreover, Fig. 3 shows 3-layers of the composite, which were sequentially added for fabrication on GCE surface corresponds to GCE (1st layer), SWCNT-Nf (2nd layer) and $\mathrm{MnO}_{2} / \mathrm{SWCNT}-\mathrm{Nf} / \mathrm{GCE}$ (3rd layer). This evidence is strongly correlated with the CVs of GCE (curve a), SWCNT-Nf (curve b) and $\mathrm{MnO}_{2} / \mathrm{SWCNT}-\mathrm{Nf} / \mathrm{GCE}$ (curve c) as shown in Fig. 2(A).

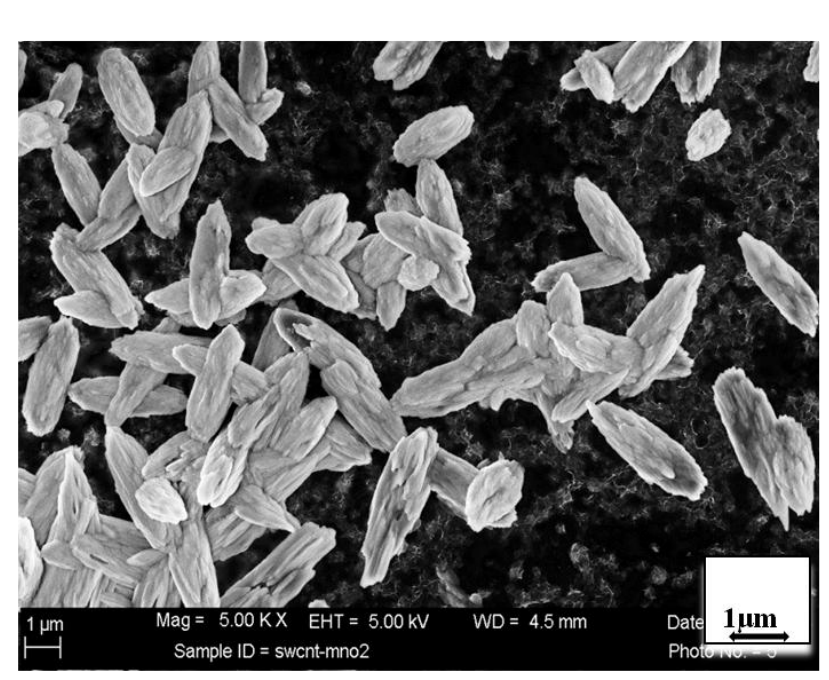

$$
1^{\text {st }} \text { layer } \quad 2^{\text {nd }} \text { layer } \quad 3^{\text {rd }} \text { layer }
$$

Fig. 3. SEM images of rice like $\mathrm{MnO}_{2}$ Nanoparticles on SWCNT-Nf/GCE.

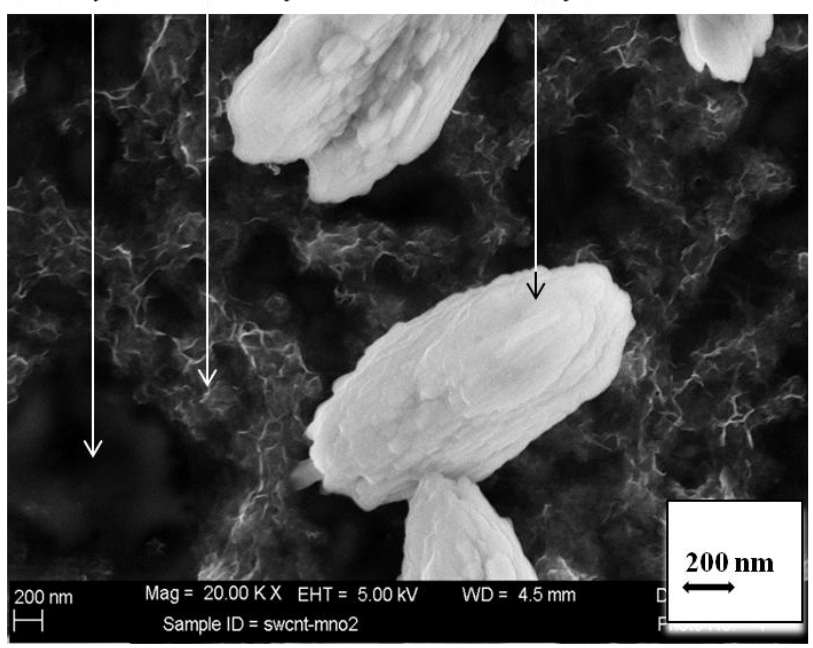

An XRD pattern of the $\mathrm{MnO}_{2}$ electrodeposited on pristine SWCNT is shown in Fig. 4. It could be observed that only SWCNT shows one sharp diffraction peak at around $25.5^{0}$ corresponding to the $\mathrm{C}(002)$ plane, and other characteristic diffraction peaks at $2 \theta$ of about $43^{0}, 53^{0}$ and $77^{0}$ are associated with C(100), C(004) and C(110) respectively. Despite the low intensity and weakly crystalline nature of electrolytic $\mathrm{MnO}_{2}$, the three major diffraction peaks of $\mathrm{MnO}_{2}$ at $2 \theta=\sim 22^{0}$, $\sim 37.2^{0}$ and $\sim 61.6^{0}$, can be assigned as the crystal planes of (110), (021), and (061) confirming the formation of $\gamma-\mathrm{MnO}_{2}[50,51]$. 


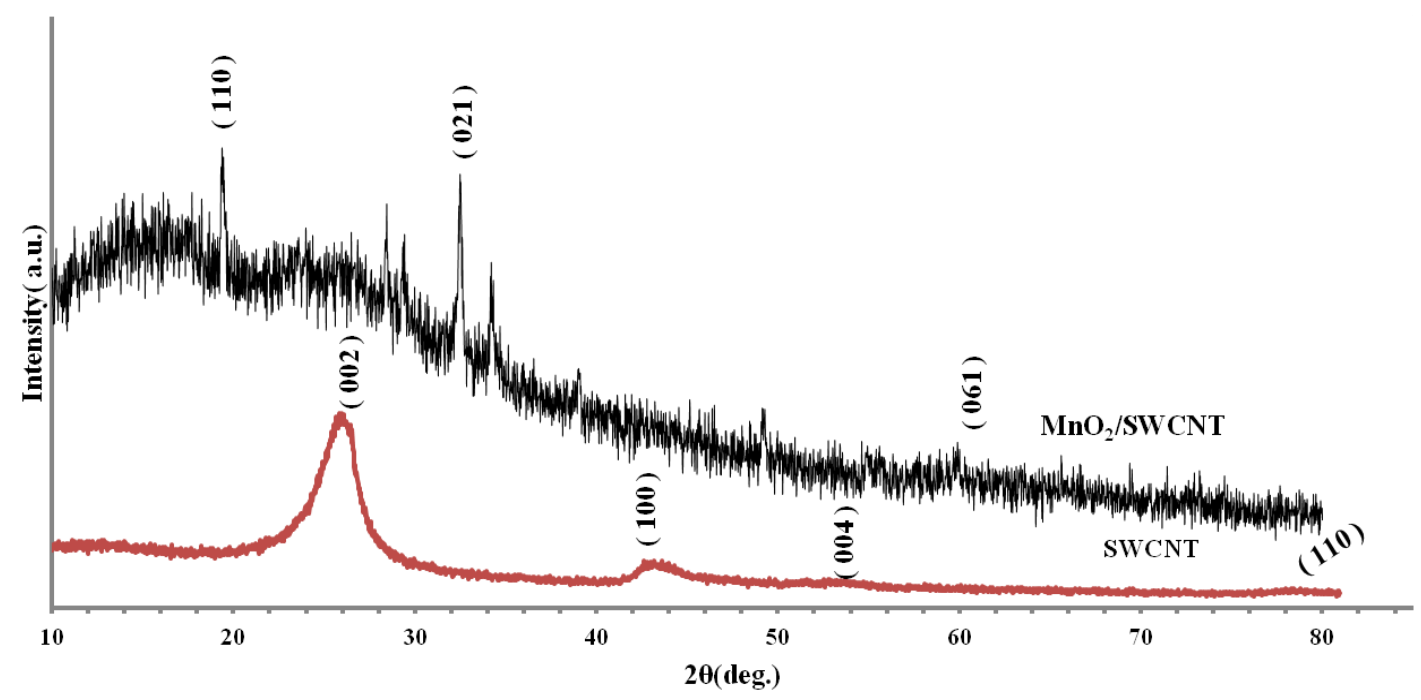

Fig. 4. XRD patterns of pristine SWCNT and electrodeposited $\mathrm{MnO}_{2}$.

\subsubsection{Electrochemical behavior of $\mathrm{H}_{2} \mathrm{O}_{2}$ at $\mathrm{MnO}_{2} / \mathrm{SWCNT-Nf/GCE}$}

The cyclic voltammetric behaviors of different electrodes are shown in Fig. 5(A) in the presence of $3 \mathrm{mM} \mathrm{H}_{2} \mathrm{O}_{2}$ in $0.1 \mathrm{M}$ PBS ( $\mathrm{pH} \mathrm{8.0)}$ ) at the scan rate $100 \mathrm{mVs}^{-1}$. No oxidation peaks were observed at bare GCE (curve $a$ ) and SWCNT-Nf/GCE (curve $b$ ). However, a broad and weak oxidation peak was found at about $+0.58 \mathrm{~V}$ for the $\mathrm{MnO}_{2} / \mathrm{SWCNT}-\mathrm{Nf} / \mathrm{GCE}$ (curve $c$ ) in the potential range of 0.0-1.0V. From Fig. 5(B), it is clear that the increase of oxidation peak current is correlated with the increase of $(3 \mathrm{mM}-18 \mathrm{mM}) \mathrm{H}_{2} \mathrm{O}_{2}$ concentration. The possible reaction mechanism could be explained in the following way: $\mathrm{MnO}_{2}$ was reduced from $\mathrm{Mn}$ (IV) to $\mathrm{Mn}$ (II or III) state by the $\mathrm{H}_{2} \mathrm{O}_{2}$ (Eq. 2), and then Mn (II or III) was electro-oxidized back to Mn (IV) at the electrode surface (Eq. 3) [52].

$$
\begin{aligned}
& \mathrm{MnO}_{2}(\mathrm{IV})+\mathrm{H}_{2} \mathrm{O}_{2} \rightarrow \mathrm{MnO}(\mathrm{II}) \text { or } \mathrm{Mn}_{2} \mathrm{O}_{3}(\mathrm{III})+\mathrm{H}_{2} \mathrm{O}+\mathrm{O}_{2} \\
& \mathrm{MnO}(\mathrm{II}) \text { or } \mathrm{Mn}_{2} \mathrm{O}_{3}(\mathrm{III}) \rightarrow \mathrm{MnO}_{2}(\mathrm{IV})+2 \mathrm{e}^{-}
\end{aligned}
$$



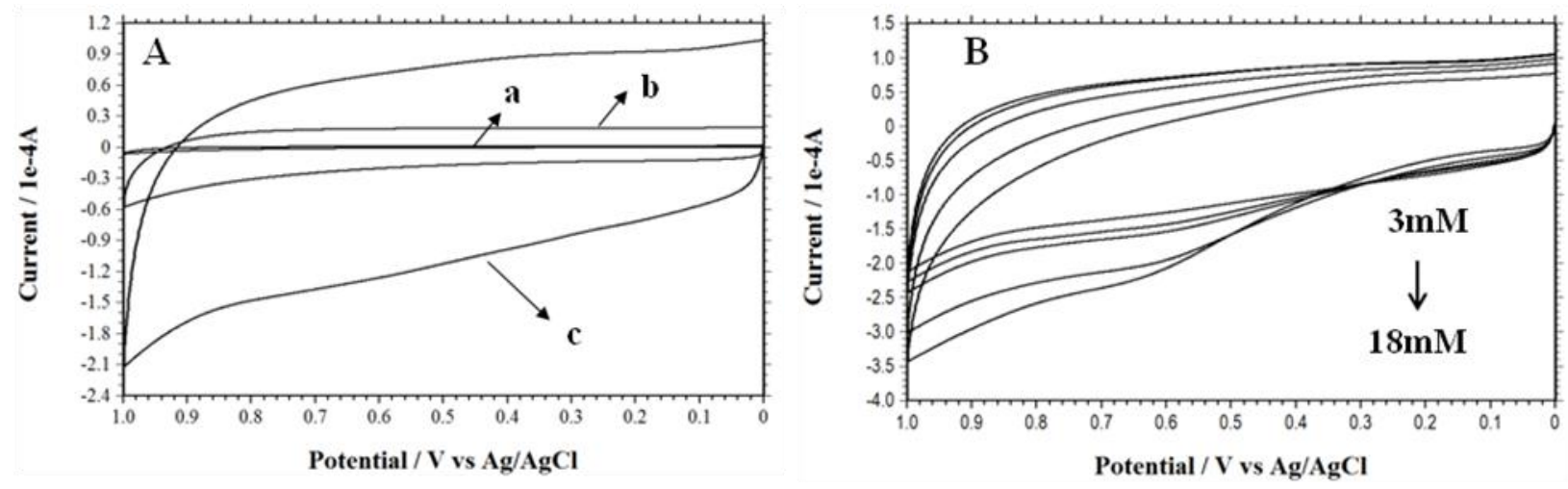

Fig. 5.(A) Cyclic voltammograms (CV) of different electrodes: (a) bare GCE, (b) SWCNT-Nf, (c) $\mathrm{MnO}_{2} / \mathrm{SWCNT}-\mathrm{Nf} / \mathrm{GCE}$ in presence of $3 \mathrm{mM}$ of $\mathrm{H}_{2} \mathrm{O}_{2}$; (B) CV of $\mathrm{MnO}_{2} / \mathrm{SWCNT}-\mathrm{Nf} / \mathrm{GCE}$ with different concentration of $\mathrm{H}_{2} \mathrm{O}_{2}(3,6,9,15$ and $18 \mathrm{mM})$ in $0.1 \mathrm{M}$ PBS (pH 8.0) at scan rate $0.1 \mathrm{~V} / \mathrm{s}$.

\subsubsection{Optimization of sensor's working properties}

Since $\mathrm{MnO}_{2}$ was the key material to react with hydrogen peroxide, therefore, its amount on the surface played the major role influencing the final performance of the sensor. Consequently, the number of scanning cycles was directly correlated to the total amount of $\mathrm{MnO}_{2}$ electrodeposited on to the surface of SWCNT-Nf nanocomposite modified GCE.

The next step was to investigate correlations between amperometric signals due to catalytic oxidation of $0.1 \mathrm{mM} \mathrm{H}_{2} \mathrm{O}_{2}$ of different numbers of scanning cycles. As shown in Fig. 6, the response current of different cycles varied due to the availability and stability of sensing material $\mathrm{MnO}_{2}$ nanoparticles on the surface. The response current observed in three successive additions of $0.1 \mathrm{mM} \mathrm{H}_{2} \mathrm{O}_{2}$ into PBS ( $\mathrm{pH} 8.0$ ) was rising up to 25 cycles. We have not observed any substantial current increase with additional continuation of scanning cycles, which could be explained by the excessive $\mathrm{MnO}_{2}$ at the surface causing deterioration of the conductivity and current responses. Based on the smooth amperometric response, the stable signal in 25 cycles was chosen to prepare $\mathrm{MnO}_{2} / \mathrm{SWCNT}-\mathrm{Nf} / \mathrm{GCE}$ for further experiments. 


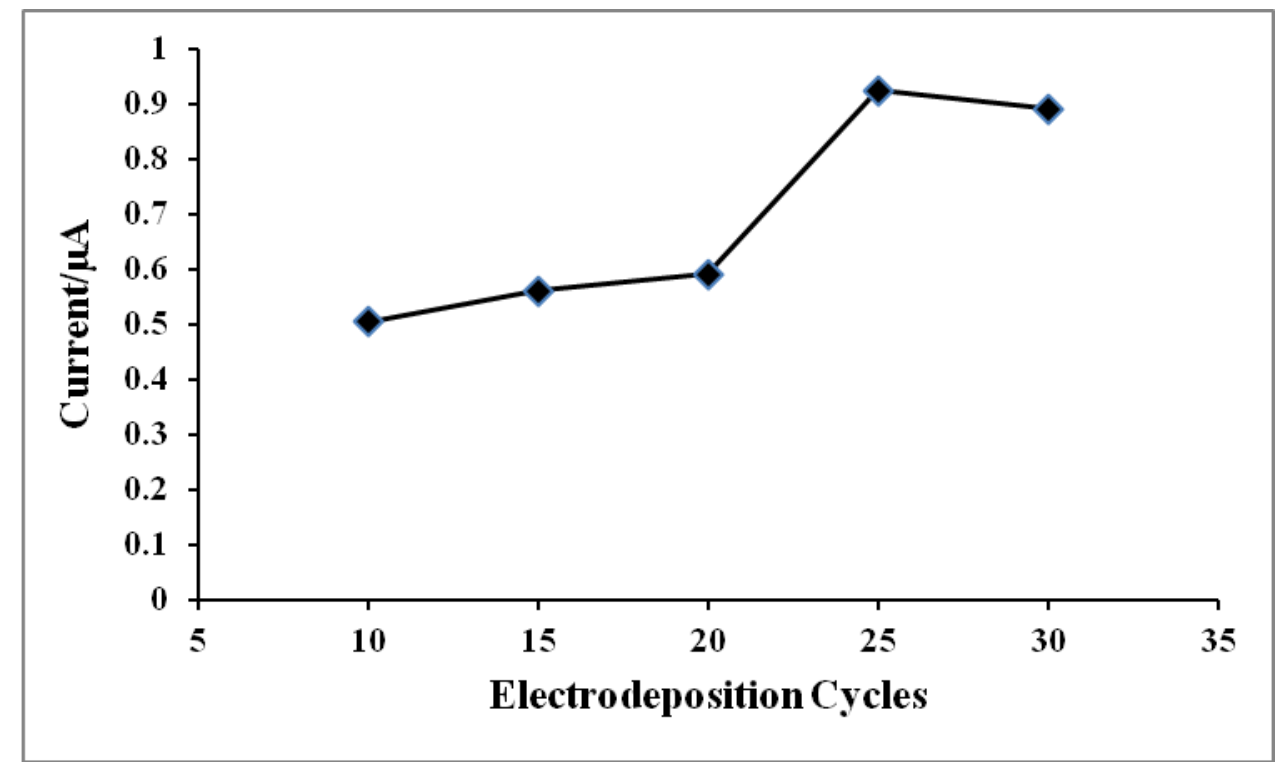

Fig. 6. Effect of electrodeposition cycles of $\mathrm{MnO}_{2}$ on the amperometric response of $0.1 \mathrm{mM} \mathrm{H}_{2} \mathrm{O}_{2}$ in $0.1 \mathrm{M}$ PBS (pH 8.0).

The effects of $\mathrm{pH}$ value and applied potential were investigated with $0.1 \mathrm{mM} \mathrm{H}_{2} \mathrm{O}_{2}$ in $0.1 \mathrm{M}$ PBS. The optimal $\mathrm{pH}$ of supporting electrolyte was selected based on the amperometric responses to the three successive additions of $0.1 \mathrm{mM} \mathrm{H}_{2} \mathrm{O}_{2}$. It was observed that the response current increased, when $\mathrm{pH}$ increased from 6.0 to 8.0, and then decreased when $\mathrm{pH}$ has grown from 8.0 to 9.0 (Fig. 7). The results of $\mathrm{pH}$ experiments have suggested that the sensor exhibited the lower catalytic ability in acidic and basic conditions of supporting electrolyte, but showed the highest catalysis at $\mathrm{pH}$ 8.0. Therefore, $\mathrm{pH} 8.0$ was chosen as the optimal value for the detection of $\mathrm{H}_{2} \mathrm{O}_{2}$.

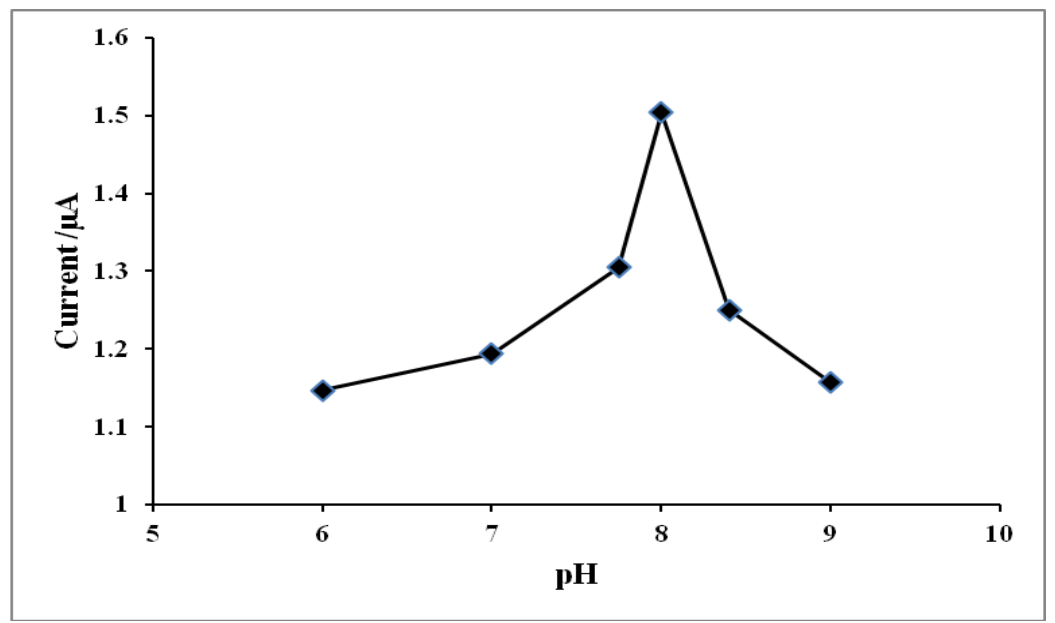

Fig. 7. Effect of $\mathrm{pH}$ on the amperometric response of $0.1 \mathrm{mM} \mathrm{H}_{2} \mathrm{O}_{2}$ in $0.1 \mathrm{M}$ PBS. 
The third optimized parameter was the working potential. The results of this set of experiments are shown in Fig. 8. It was found that the steady-state current response clearly increased with working potential from 0.2 to $0.7 \mathrm{~V}$, and then decreased sharply from 0.7 to $0.8 \mathrm{~V}$. Therefore, 0.7 $\mathrm{V}$ was selected as the working potential for amperometric detection of $\mathrm{H}_{2} \mathrm{O}_{2}$.

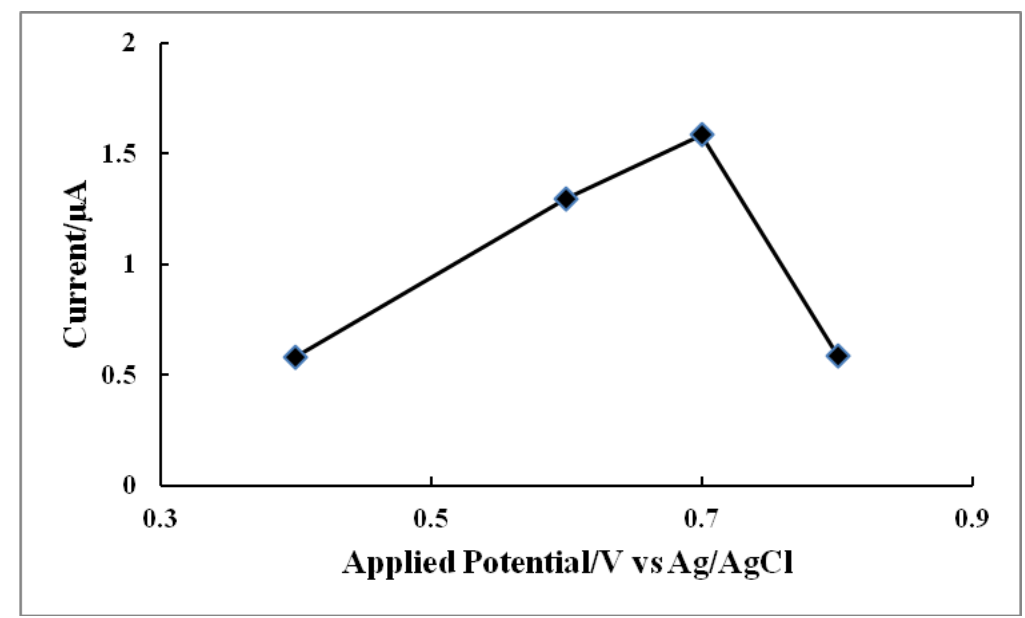

Fig. 8. Effect of applied potential on the amperometric response of $0.1 \mathrm{mM} \mathrm{H}_{2} \mathrm{O}_{2}$ in $0.1 \mathrm{M} \mathrm{PBS}$ $(\mathrm{pH} 8.0)$

\subsubsection{Detection limit, linearity, and film status of the $\mathrm{MnO}_{2} / \mathrm{SWCNT-Nf/GCE}$}

Under optimized operating conditions, the performance of the proposed non-enzymatic sensor showed a rapid and stable response towards various concentrations of $\mathrm{H}_{2} \mathrm{O}_{2}$. As shown in Fig. 9, the current-time curves were obtained upon successive addition of different concentrations of $\mathrm{H}_{2} \mathrm{O}_{2}$ into 0.1M PBS ( $\mathrm{pH}$ 8.0). The calibration curve of the sensor and the regression equation are displayed in Fig. 9 with regression equation of:

$I p(\boldsymbol{\mu A})=0.0126 \boldsymbol{x}+\boldsymbol{0 . 3 9 3}$, where $\boldsymbol{x}$ is the concentration of $\mathrm{H}_{2} \mathrm{O}_{2}$ in $\mu \mathrm{M}$

The linearity range of this calibration curve was from 0.005 to $3.0 \mathrm{mM}$. From the slope (S) of $0.0126 \mu \mathrm{A} / \mu \mathrm{M}$, the limit of detection (LOD) was calculated to be $0.52 \times 10^{-6} \mathrm{M}(17.7 \mathrm{ppb})$ using the following equation [53].

$\mathrm{LOD}=\mathrm{SD}_{\text {background }} / \mathrm{S}$, where $\mathrm{S}$ is slop or sensitivity, $\mathrm{SD}$ : standard deviation 

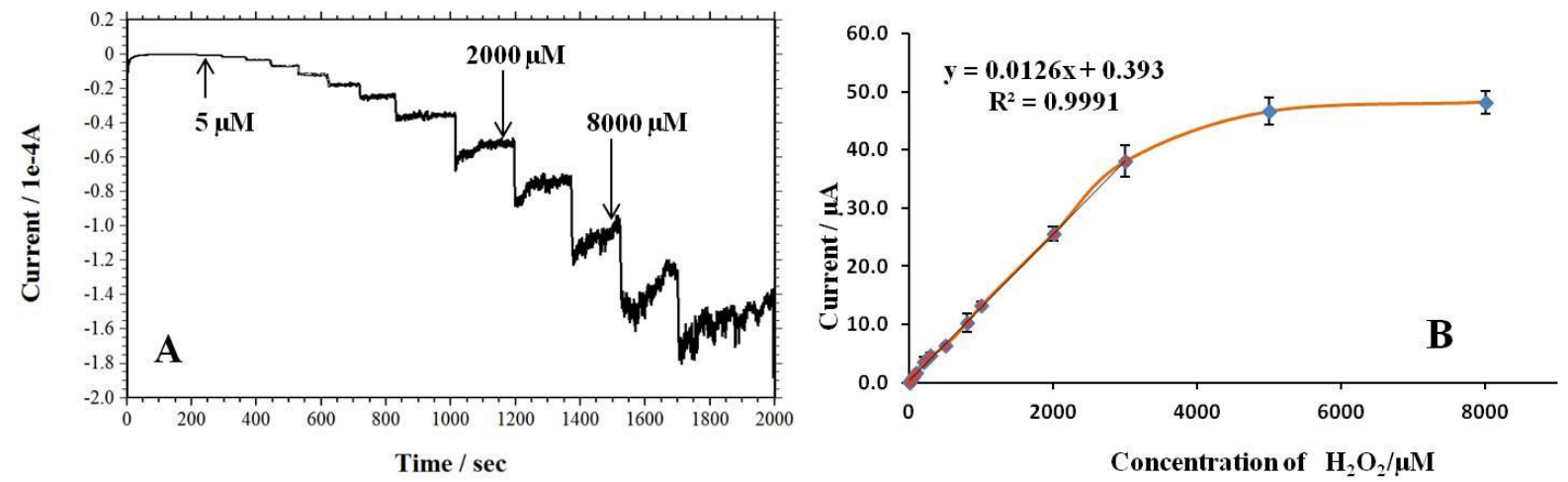

Fig. 9. (A) Current-time curves obtained on $\mathrm{MnO}_{2} / \mathrm{SWCNT}-\mathrm{Nf} / \mathrm{GCE}$ upon successive addition of different concentration of $\mathrm{H}_{2} \mathrm{O}_{2}$ into $0.1 \mathrm{M}$ PBS ( $\mathrm{pH} 8.0$ ) at $0.7 \mathrm{~V}$. (B) Correlation between catalytic current and the concentration of $\mathrm{H}_{2} \mathrm{O}_{2}$.

In addition, the status of the sensor was also evaluated at different time duration in the amperometric measurement. For this purpose, the time duration of I-T curve was extended up to 2500s with adding $\mathrm{H}_{2} \mathrm{O}_{2}$ in regular sequences. In addition, cyclic voltammetry was employed to investigate the film condition in terms of electrocatalytic oxidation of $\mathrm{H}_{2} \mathrm{O}_{2}$ on electrode exposed at different time duration in amperometric measurements. The result showed that the film condition was quite good up to 2000s though the response current signal started to decrease after 1000s during amperometric measurement. After 2000s, the amperometric response was completely irregular and unstable. The experimental details and results are described in the Supplementary Material (SM).

A general comparison of working conditions (linear range, detection limit and working $\mathrm{pH}$ ) of our non-enzymatic $\mathrm{MnO}_{2}$ /SWCNT-Nf/GCE sensor with sensors previously reported in literature is summarized in Table 1. It could be seen that simplicity of our sensor has not affected the broad working linear range and low detection limit within optimal $\mathrm{pH}$.

Table 1. Comparison of different $\mathrm{H}_{2} \mathrm{O}_{2}$ Sensors

\begin{tabular}{|l|c|l|l|l|}
\hline Modified Electrode & $\begin{array}{c}\text { Linear range } \\
(\boldsymbol{\mu M})\end{array}$ & $\begin{array}{c}\text { Detection limit } \\
(\boldsymbol{\mu M})\end{array}$ & $\mathbf{p H}$ & Reference \\
\hline HRP/DNA/Au & $10.0-9700$ & 50.0 & 7.0 & {$[54]$} \\
\hline NanoAg/DNA networks & $4.0-1600$ & 1.7 & 7.0 & {$[55]$} \\
\hline
\end{tabular}




\begin{tabular}{|l|c|l|l|l|}
\hline Cryptomelane-type $\mathrm{MnO}_{2} / \mathrm{CPE}$ & $100-6900$ & 2.0 & 7.4 & {$[56]$} \\
\hline Ag NPs/graphite substrate & $50-2500$ & 1.0 & $\begin{array}{l}\text { Not } \\
\text { reported }\end{array}$ & {$[57]$} \\
\hline $\begin{array}{l}\mathrm{TiO}_{2} \text { horseradish peroxidase } \\
\text { gold nano-seeds/GCE }\end{array}$ & $41-630$ & 5.9 & 7.0 & {$[58]$} \\
\hline $\mathrm{NP} \mathrm{PtCo}$ & $50-800$ & 1.0 & 7.0 & {$[59]$} \\
\hline PPy-Co NCs carbon & $20-1000$ & 2.1 & $5.0-7.0$ & {$[60]$} \\
\hline $\begin{array}{l}\text { PdCu/Screen printed } \\
\text { electrode(SPCE) }\end{array}$ & $500-1100$ & 0.7 & $\begin{array}{l}\text { Not } \\
\text { reported }\end{array}$ & {$[53]$} \\
\hline $\begin{array}{l}\text { MnO } \\
\text { /SWCNT-Nf/GCE }\end{array}$ & $\mathbf{5 . 0 - 3 0 0 0}$ & $\mathbf{0 . 5}$ & $\mathbf{7 . 0}-\mathbf{8 . 0}$ & This study \\
\hline
\end{tabular}

\subsection{Testing $\mathrm{H}_{2} \mathrm{O}_{2}$ sensor in environmental setting}

\subsubsection{Evaluation of Selectivity, reproducibility and stability of the $\mathrm{H}_{2} \mathrm{O}_{2}$ sensor}

Several common metal ion and anions were investigated for their possible interference with the amperometric determination of $\mathrm{H}_{2} \mathrm{O}_{2}$. The interference experiments were performed in $0.1 \mathrm{M}$ PBS solution ( $\mathrm{pH}$ 8.0) under optimal conditions by comparing the response current of $0.1 \mathrm{mM} \mathrm{H}_{2} \mathrm{O}_{2}$ including each interfering substance with that of $0.1 \mathrm{mM} \mathrm{H}_{2} \mathrm{O}_{2}$ alone. The results showed that 10 fold concentration of $\mathrm{Ca}^{2+}, \mathrm{Mg}^{2+}, \mathrm{Fe}^{3+}$ and $\mathrm{HCO}_{3}{ }^{-}$interfered slightly, which was possibly attributed to the fact that these ions could catalyze $\mathrm{H}_{2} \mathrm{O}_{2}$ and generate $\mathrm{OH}$ radicals. Tested $\mathrm{Na}^{+}$, $\mathrm{Cu}^{2+}, \mathrm{Ni}^{2+}, \mathrm{Cl}^{-}, \mathrm{NO}_{3}{ }^{-}, \mathrm{SO}_{4}{ }^{2-}$, glucose and citrate were hardly interfered with the detection of $\mathrm{H}_{2} \mathrm{O}_{2}$.

The reproducibility and stability of the sensor were also tested. The reproducibility was determined from the response to $0.02 \mathrm{mM} \mathrm{H}_{2} \mathrm{O}_{2}$ at five $\mathrm{MnO}_{2}$ /SWCNT-Nf/GCE electrodes prepared separately, and the relative standard deviation (R.S.D.) of $2.1 \%$ was obtained. The long-term stability was explored by measuring $0.02 \mathrm{mM} \mathrm{H}_{2} \mathrm{O}_{2}$, and it retained $89.3 \%$ of the original value after 50 consecutive measurements (Table 2). 
Table 2. Results of determination of $\mathrm{H}_{2} \mathrm{O}_{2}$ in the presence of interfering ions

\begin{tabular}{|l|l|l|}
\hline Interferent & Concentration $(\mathrm{mM})$ & Current ratio $^{\mathrm{a}}$ \\
\hline $\mathrm{Cu}^{2+}$ & 1.0 & 0.89 \\
\hline $\mathrm{Fe}^{3+}$ & 1.0 & 0.80 \\
\hline $\mathrm{Ni}^{2+}$ & 1.0 & 0.95 \\
\hline $\mathrm{Mg}^{2+}$ & 1.0 & 0.65 \\
\hline $\mathrm{Ca}^{2+}$ & 1.0 & 0.75 \\
\hline $\mathrm{Na}^{+}$ & 1.0 & 0.98 \\
\hline $\mathrm{HCO}_{3}^{-}$ & 1.0 & 0.77 \\
\hline $\mathrm{Cl}^{-}$ & 1.0 & 0.98 \\
\hline $\mathrm{NO}_{3}{ }^{-}$ & 1.0 & 0.95 \\
\hline $\mathrm{SO}_{4}{ }^{2-}$ & 1.0 & 0.98 \\
\hline $\mathrm{Citrate}^{2+}$ & 1.0 & 0.91 \\
\hline $\mathrm{Glucose}^{2}$ & 1.0 & 0.92 \\
\hline
\end{tabular}

${ }^{\mathrm{a}}$ Ratio of currents for mixtures of interferents and $0.1 \mathrm{mM} \mathrm{H}_{2} \mathrm{O}_{2}$ compared to that for $0.1 \mathrm{mM} \mathrm{H}_{2} \mathrm{O}_{2}$ alone.

\subsubsection{Non-standardized sample analysis}

The feasibility check of the developed sensor for the practical applications was carried out by analyzing the natural water samples collected from a nearby ditch holding urban stormwater runoff. No detectable amount of $\mathrm{H}_{2} \mathrm{O}_{2}$ was initially found in that water. The collected water samples were spiked with different known concentrations of $\mathrm{H}_{2} \mathrm{O}_{2}$ and tested with the sensor. The recoveries of hydrogen peroxide samples with concentrations of $5 \mu \mathrm{M}$ (sample 2 ), $10 \mu \mathrm{M}$ (sample 3), $20 \mu \mathrm{M}$ (sample 4) and $50 \mu \mathrm{M}$ (sample 5) are shown in Table 3. The results have confirmed that the sensor has a potential in detection of hydrogen peroxide directly in unaltered environmental samples. Sample 1 served as control; all analysis were repeated 3 times $(n=3)$.

Table 3. Determination of concentration of $\mathrm{H}_{2} \mathrm{O}_{2}$ in environmental water samples $(n=3)$

\begin{tabular}{|l|l|l|l|l|}
\hline Sample & Added $\mathrm{H}_{2} \mathrm{O}_{2}(\mu \mathrm{M})$ & $\begin{array}{l}\text { Measured } \mathrm{H}_{2} \mathrm{O}_{2} \\
(\mu \mathrm{M})\end{array}$ & Recovery(\%) & $\mathrm{RSD}(\%)$ \\
\hline 1 & 0 & $<\mathrm{DL}$ & & \\
\hline
\end{tabular}




\begin{tabular}{|l|l|l|l|l|}
\hline 2 & 5 & 5.4 & 108 & 2.4 \\
\hline 3 & 10 & 11.2 & 112 & 1.8 \\
\hline 4 & 20 & 19.9 & 99.5 & 2.4 \\
\hline 5 & 50 & 55.7 & 111.5 & 2.1 \\
\hline
\end{tabular}

\section{Conclusions}

In this work, a non-enzymatic $\mathrm{H}_{2} \mathrm{O}_{2}$ sensor was design and manufactured as $\mathrm{MnO}_{2} / \mathrm{SWCNTs-Nf}$ nanocomposite modified glassy carbon electrode to measure wide-range concentration of hydrogen peroxide in water matrix. The proposed sensor showed excellent performance to the electrochemical response of $\mathrm{H}_{2} \mathrm{O}_{2}$ under optimized condition of $\mathrm{pH}$ 8.0, applied potential $0.7 \mathrm{~V}$ and 25 electrodeposition cycles. The linearity range of calibration curve was found from $5.0 \times$ $10^{-6}$ to $3.0 \times 10^{-3} \mathrm{M}$, and the detection limit was $0.52 \times 10^{-6} \mathrm{M}(17.7 \mathrm{ppb})$. The low detection limit, wide linear range and high sensitivity of this sensor provide the possibility for reliable detection of $\mathrm{H}_{2} \mathrm{O}_{2}$ in environmental samples.

\section{Acknowledgements}

The authors would like to special thanks to Dr. Hiroyasu Tachikawa for using his electrochemical workstation, and also acknowledge financial support from the National Science Foundation, award NSF EPSCoR \# 362492-190200-01\NSFEPS-0903787, NSF-CREST\# HRD 0833178 and RCMI award \# 8G12MD007581.

\section{References:}

1. Ludwig, E. and P. Eyer, Reactivity of Glutathione Adducts of 4-(Dimethylamino)phenol. Involvement of Reactive Oxygen Species during the Interaction with Oxyhemoglobin. Chemical Research in Toxicology, 1995. 8(3): p. 363-368.

2. Qi, L., et al., Study on the possibility of hydrogen peroxide pretreatment and plant system to remediate soil pollution. Chemosphere, 2004. 57(10): p. 1439-1447.

3. Fernando, C.D. and P. Soysa, Optimized enzymatic colorimetric assay for determination of hydrogen peroxide (H2O2) scavenging activity of plant extracts. MethodsX, 2015. 2(0): p. 283-291.

4. $\quad$ Anjum, S., et al., Non-enzymatic hydrogen peroxide sensor by electroreduction of $p$ nitrophenyl aldehyde in the presence of nitrous acid on glassy carbon electrode. Journal of Electroanalytical Chemistry, 2015. 750(0): p. 74-78. 
5. Maicaneanu, A., et al., Physical-chemical and electrochemical characterization of $\mathrm{Fe}$ exchanged natural zeolite applied for obtaining of hydrogen peroxide amperometric sensors. Chemie der Erde - Geochemistry, 2014. 74(4): p. 653-660.

6. Lugo-Morales, L.Z., et al., Enzyme-Modified Carbon-Fiber Microelectrode for the Quantification of Dynamic Fluctuations of Nonelectroactive Analytes Using Fast-Scan Cyclic Voltammetry. Analytical Chemistry, 2013.

7. Azadbakht, A., M.B. Gholivand, and S. Menati, Nanomolar detection of hydrogen peroxide at a nano-structured adducts of diorganotin dichlorides multiwall carbon nanotube modified glassy carbon electrode. Electrochim. Acta, 2012. 78(Copyright (C) 2013 American Chemical Society (ACS). All Rights Reserved.): p. 82-91.

8. Xu, X., et al., Nitrogen-Doped Carbon Nanotubes: High Electrocatalytic Activity toward the Oxidation of Hydrogen Peroxide and Its Application for Biosensing. ACS Nano, 2010. 4(Copyright (C) 2013 American Chemical Society (ACS). All Rights Reserved.): p. $4292-4298$.

9. $\quad \mathrm{Li}, \mathrm{X}$., et al., Real-Time Electrochemical Monitoring of Cellular H2O2 Integrated with In Situ Selective Cultivation of Living Cells Based on Dual Functional Protein Microarrays at Au-TiO2 Surfaces. Anal. Chem. (Washington, DC, U. S.), 2010. 82(Copyright (C) 2013 American Chemical Society (ACS). All Rights Reserved.): p. 6512-6518.

10. Hurdis, E.C. and H. Romeyn, Accuracy of Determination of Hydrogen Peroxide by Cerate Oxidimetry. Analytical Chemistry, 1954. 26(2): p. 320-325.

11. Zeng, Y., et al., Determination of hydrogen peroxide residue in food using CdS quantum dots as fluorescence probes. Adv. Mater. Res. (Durnten-Zurich, Switz.), 2012. 455456(Copyright (C) 2013 American Chemical Society (ACS). All Rights Reserved.): p. 1189-1194.

12. Jiang, Z., et al., A simple and sensitive fluorescence quenching method for the determination of $\mathrm{H} 2 \mathrm{O} 2$ using Rhodamine B and $\mathrm{Fe} 3 \mathrm{O} 4$ nanocatalyst. J. Fluoresc., 2011. 21(Copyright (C) 2013 American Chemical Society (ACS). All Rights Reserved.): p. 2015-2020.

13. Gao, Y., et al., Fluorometric method for the determination of hydrogen peroxide and glucose with Fe3O4 as catalyst. Talanta, 2011. 85(Copyright (C) 2013 American Chemical Society (ACS). All Rights Reserved.): p. 1075-1080.

14. Li, Y.-z. and A. Townshend, Evaluation of the adsorptive immobilization of horseradish peroxidase on PTFE tubing in flow systems for hydrogen peroxide determination using fluorescence detection. Anal. Chim. Acta, 1998. 359(Copyright (C) 2013 American Chemical Society (ACS). All Rights Reserved.): p. 149-156.

15. Matsubara, C., N. Kawamoto, and K. Takamura, Oxo[5, 10, 15, 20-tetra(4pyridyl)porphyrinato]titanium(IV): an ultra-high sensitivity spectrophotometric reagent for hydrogen peroxide. Analyst, 1992. 117(11): p. 1781-1784.

16. Klassen, N.V., D. Marchington, and H.C.E. McGowan, H2O2 Determination by the I3Method and by KMnO4 Titration. Analytical Chemistry, 1994. 66(18): p. 2921-2925.

17. Nogueira, R.F.P., M.C. Oliveira, and W.C. Paterlini, Simple and fast spectrophotometric determination of $\mathrm{H} 2 \mathrm{O} 2$ in photo-Fenton reactions using metavanadate. Talanta, 2005. 66(1): p. 86-91.

18. Hoshino, M., et al., Spectrophotometric determination of hydrogen peroxide with osmium(VIII) and m-carboxyphenylfluorone. Spectrochimica Acta Part A: Molecular and Biomolecular Spectroscopy, 2014. 117(0): p. 814-816. 
19. Li, X., et al., Sensitive and selective chemiluminescence assay for hydrogen peroxide in exhaled breath condensate using nanoparticle-based catalysis. Spectrochim. Acta, Part A, 2013. 107(Copyright (C) 2013 American Chemical Society (ACS). All Rights Reserved.): p. 311-316.

20. Parajuli, S. and W. Miao, Sensitive Determination of Triacetone Triperoxide Explosives Using Electrogenerated Chemiluminescence. Anal. Chem. (Washington, DC, U. S.), 2013. 85(Copyright (C) 2013 American Chemical Society (ACS). All Rights Reserved.): p. 8008-8015.

21. Vdovenko, M.M., et al., FeIII-TAML activator: A potent peroxidase mimic for chemiluminescent determination of hydrogen peroxide. Talanta, 2014. 125(0): p. 361365.

22. Bian, X., et al., Nanocomposites of palladium nanoparticle-loaded mesoporous carbon nanospheres for the electrochemical determination of hydrogen peroxide. Talanta, 2012. 99: p. 256-261.

23. Ni, P., et al., Facile synthesis of Prussian blue @ gold nanocomposite for nonenzymatic detection of hydrogen peroxide. RSC Advances, 2013. 3(36): p. 15987-15992.

24. Gatselou, V.A., et al., Rhodium nanoparticle-modified screen-printed graphite electrodes for the determination of hydrogen peroxide in tea extracts in the presence of oxygen. Talanta, 2015. 134(0): p. 482-487.

25. Lin, Y., et al., Advances toward bioapplications of carbon nanotubes. Journal of Materials Chemistry, 2004. 14(4): p. 527-541.

26. Baughman, R.H., A.A. Zakhidov, and W.A. de Heer, Carbon Nanotubes--the Route Toward Applications. Science, 2002. 297(5582): p. 787-792.

27. Banks, C.E., et al., Investigation of modified basal plane pyrolytic graphite electrodes: definitive evidence for the electrocatalytic properties of the ends of carbon nanotubes. Chemical Communications, 2004(16): p. 1804-1805.

28. Chen, G., L. Zhang, and J. Wang, Miniaturized capillary electrophoresis system with a carbon nanotube microelectrode for rapid separation and detection of thiols. Talanta, 2004. 64(4): p. 1018-1023.

29. Qu, S., et al., Magnetic loading of carbon nanotube/nano-Fe3O4 composite for electrochemical sensing. Talanta, 2007. 71(3): p. 1096-1102.

30. Wei, B., et al., Solubilization of carbon nanotubes by cellulose xanthate toward the fabrication of enhanced amperometric detectors. Carbon, 2010. 48(5): p. 1380-1387.

31. Fu, Y., L. Zhang, and G. Chen, Preparation of a carbon nanotube-copper nanoparticle hybrid by chemical reduction for use in the electrochemical sensing of carbohydrates. Carbon, 2012. 50(7): p. 2563-2570.

32. Husmann, S., E. Nossol, and A.J.G. Zarbin, Carbon nanotube/Prussian blue paste electrodes: Characterization and study of key parameters for application as sensors for determination of low concentration of hydrogen peroxide. Sensors and Actuators B: Chemical, 2014. 192(0): p. 782-790.

33. Sun, Y., et al., Real-time electrochemical detection of hydrogen peroxide secretion in live cells by Pt nanoparticles decorated graphene-carbon nanotube hybrid paper electrode. Biosensors and Bioelectronics, 2015. 68(0): p. 358-364.

34. Zhou, W., I.E. Wachs, and C.J. Kiely, Nanostructural and chemical characterization of supported metal oxide catalysts by aberration corrected analytical electron microscopy. Current Opinion in Solid State and Materials Science, 2012. 16(1): p. 10-22. 
35. Chang, M.-H., H.-S. Liu, and C.Y. Tai, Preparation of copper oxide nanoparticles and its application in nanofluid. Powder Technology, 2011. 207(1-3): p. 378-386.

36. Liu, J., et al., Crystallinity-Controlled Synthesis of Zirconium Oxide Thin Films on Nitrogen-Doped Carbon Nanotubes by Atomic Layer Deposition. The Journal of Physical Chemistry C, 2012. 116(27): p. 14656-14664.

37. Roushani, M., et al., Amperometric detection of hydrogen peroxide at nano-ruthenium oxide/riboflavin nanocomposite-modified glassy carbon electrodes. Electrochimica Acta, 2013. 113(0): p. 134-140.

38. Heli, H. and J. Pishahang, Cobalt oxide nanoparticles anchored to multiwalled carbon nanotubes: Synthesis and application for enhanced electrocatalytic reaction and highly sensitive nonenzymatic detection of hydrogen peroxide. Electrochimica Acta, 2014. 123(0): p. 518-526.

39. Butwong, N., et al., A sensitive nonenzymatic hydrogen peroxide sensor using cadmium oxide nanoparticles/multiwall carbon nanotube modified glassy carbon electrode. Journal of Electroanalytical Chemistry, 2014. 717-718(0): p. 41-46.

40. Thandavan, K., et al., Hydrogen peroxide biosensor utilizing a hybrid nano-interface of iron oxide nanoparticles and carbon nanotubes to assess the quality of milk. Sensors and Actuators B: Chemical, 2015. 215(0): p. 166-173.

41. Yan, J., et al., Fast and reversible surface redox reaction of graphene-MnO2 composites as supercapacitor electrodes. Carbon, 2010. 48(13): p. 3825-3833.

42. Yao, S., et al., A highly sensitive hydrogen peroxide amperometric sensor based on $\mathrm{MnO} 2$ nanoparticles and dihexadecyl hydrogen phosphate composite film. Analytica Chimica Acta, 2006. 557(1-2): p. 78-84.

43. Mahmoudian, M.R., et al., Facile preparation of MnO2 nanotubes/reduced graphene oxide nanocomposite for electrochemical sensing of hydrogen peroxide. Sensors and Actuators B: Chemical, 2014. 201(0): p. 526-534.

44. Luo, L., et al., Non-enzymatic hydrogen peroxide sensor based on MnO2-ordered mesoporous carbon composite modified electrode. Electrochimica Acta, 2012. 77(0): p. 179-183.

45. Liu, S., et al., A novel non-enzymatic hydrogen peroxide sensor based on Mnnitrilotriacetate acid (Mn-NTA) nanowires. Talanta, 2010. 81(1-2): p. 727-731.

46. Zhang, S., Q. Sheng, and J. Zheng, Synthesis of Ag-HNTs-MnO2 nanocomposites and their application for nonenzymatic hydrogen peroxide electrochemical sensing. RSC Advances, 2015. 5(34): p. 26878-26885.

47. $\mathrm{Xu}, \mathrm{B}$., et al., A highly sensitive hydrogen peroxide amperometric sensor based on MnO2-modified vertically aligned multiwalled carbon nanotubes. Analytica Chimica Acta, 2010. 674(1): p. 20-26.

48. Larabi-Gruet, N., et al., Studies of electrodeposition from Mn(II) species of thin layers of birnessite onto transparent semiconductor. Electrochimica Acta, 2008. 53(24): p. 72817287.

49. Manivel, A., et al., Medium effects on the electro-deposition of MnO2 on glassy carbon electrode: A comparative study in alkane, perfluoro alkane carboxylic acids and methanesulphonic acid. Electrochimica Acta, 2007. 52(28): p. 7841-7848.

50. Devaraj, S. and N. Munichandraiah, Effect of Crystallographic Structure of MnO2 on Its Electrochemical Capacitance Properties. The Journal of Physical Chemistry C, 2008. 112(11): p. 4406-4417. 
51. Xie, X. and L. Gao, Characterization of a manganese dioxide/carbon nanotube composite fabricated using an in situ coating method. Carbon, 2007. 45(12): p. 23652373.

52. Bai, Y.-H., et al., Relationship between Nanostructure and Electrochemical/Biosensing Properties of $\mathrm{MnO} 2$ Nanomaterials for H2O2/Choline. The Journal of Physical Chemistry C, 2008. 112(48): p. 18984-18990.

53. Uzunoglu, A., A.D. Scherbarth, and L.A. Stanciu, Bimetallic PdCu/SPCE non-enzymatic hydrogen peroxide sensors. Sensors and Actuators B: Chemical, 2015. 220(0): p. 968976.

54. Song, Y., et al., A novel hydrogen peroxide sensor based on horseradish peroxidase immobilized in DNA films on a gold electrode. Sensors and Actuators B: Chemical, 2006. 114(2): p. 1001-1006.

55. Cui, K., et al., A novel hydrogen peroxide sensor based on Ag nanoparticles electrodeposited on DNA-networks modified glassy carbon electrode. Electrochemistry Communications, 2008. 10(4): p. 663-667.

56. Lin, Y., X. Cui, and L. Li, Low-potential amperometric determination of hydrogen peroxide with a carbon paste electrode modified with nanostructured cryptomelane-type manganese oxides. Electrochemistry Communications, 2005. 7(2): p. 166-172.

57. He, X., et al., Building Ag nanoparticle 3D catalyst via Na2Ti3O7 nanowires for the detection of hydrogen peroxide. Sensors and Actuators B: Chemical, 2010. 144(1): p. 289-294.

58. Wang, Y., et al., Direct electrochemistry and bioelectrocatalysis of horseradish peroxidase based on gold nano-seeds dotted TiO2 nanocomposite. Biosensors and Bioelectronics, 2010. 25(11): p. 2442-2446.

59. $\mathrm{Xu}, \mathrm{C}$., et al., Nanoporous platinum-cobalt alloy for electrochemical sensing for ethanol, hydrogen peroxide, and glucose. Analytica Chimica Acta, 2013. 780(0): p. 20-27.

60. Marimuthu, T., et al., Synthesis and characterization of non-enzymatic hydrogen peroxide sensor of polypyrrole coated cobalt nanocomposites. Sensors and Actuators B: Chemical, 2014. 202(0): p. 1037-1043. 